Richard A. Spinello

\title{
Review: Vernetzt gespalten: Der Digital Divide in ethischer Perspektive
}

\section{Abstract:}

Review of Rupert M. Scheule, Rafael Capurro and Thomas Hausmanninger (editors): Vernetzt gespalten: Der Digital Divide in ethischer Perspektive München: Wilhelm Fink Verlag, 2004

\section{Agenda}

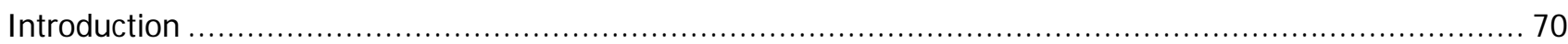

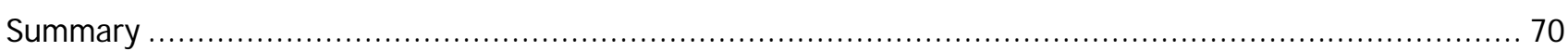

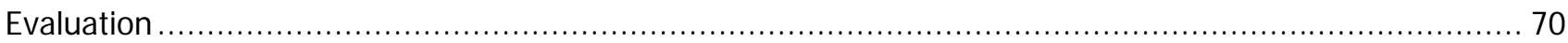

\section{Author:}

Dr. Richard A. Spinello:

- Organization and contact address: Carroll School of Management, Department of Operations \& Strategic Management, Fulton Hall 350, Boston College, Chestnut Hill, MA 02467-3838

- Telephone, email and personal homepage: 617552 1189, $\square$ richard.spinello@bc.edu,

ghttp://www2.bc.edu/ spinello 


\section{Introduction}

This book is a collection of essays centered on the broad theme of the digital divide. It is the third volume in a series of books published by the Information Center for Information Ethics (ICIE). Regrettably, this work is only available in German, so its audience will be fairly limited. That is unfortunate given the exceptional quality of the essays included and the breadth of topics that are covered. Similar anthologies such as The Digital Divide: Facing a Crisis or Creating a Myth (ed. B. Compaine), have been published on this topic. Like Vernetzt, that work too presents a variety of perspectives on the digital divide, but it is more eclectic and less coherent. The problem of a "digital divide" has been thematized in the work of philosophers like Manuel Castells, who is often cited in this book. In his many writings Castells has emphasized that the centrality of the Internet in social and economic life marginalizes those without access. Thus, he has maintained that the "differentiation between Internet-haves and have-nots adds a fundamental cleavage to existing sources of inequality" (Castells, 2001).

\section{Summary}

Vernetzt gespalten begins with a provocative "trialog" between the three co-editors, Professors Capurro, Scheule, and Hausmanninger. This unique format exposes the reader to a revealing debate about the main issues of the book, as it provides a context for the essays that will follow in subsequent sections. With the help of philosophers like Lyotard, the trialog ponders, among other things, abstract issues such as the difference between conceiving the network (Netz) as a tool (Werkzeug) or as a critical communications medium. But it also delves into more concrete topics as it tries to assess the gravity of the digital divide as a social and economic problem. The trialog immediately engages the reader about the plight of those without connectivity as it puts the issue of a digital divide into a proper perspective.

This introduction or trialog is the first part of the book and it is followed by five sections which follow in a logical progression. The second part ("Was Trennt Der Digital Divide") deals with the various ways in which the Interent-haves and have-nots are divided. One essay focuses on "cybergeography," presenting comprehensive data about the severity and scope of the problem. Various studies are cited from both the private and public sectors that have attempted to measure the extent of the digital divide along different dimensions. One such study, for example, finds that households with incomes of $\$ 75,000$ and over are twenty times more likely to more likely to have Internet access than those at lower income levels, and 9 times more likely to have computer access. Even in the midst of prosperous and well-educated communities in countries like the United States, the disparity between the information "haves" and "have nots" is glaring. A second essay in Part II examines the various forms of exclusion from cyberspace such as the difference between active and passive exclusion.

With the nature of the problem well-defined, the third part of this book focuses on why it is essential to overcome the digital divide with essays on "culture versus globalization" and "information asceticism." The fourth part concerns the basic reasons for overcoming this divide. In the essays that comprise this section several key themes are orchestrated including "information justice" (Informationgerechtigkeit), deliberative democracy, and an "emancipation Aesthetic." The fifth part, called "Ways to Overcome the Digital Divide," presents some possible practical solutions. One essay in this section on open source software and the "gift economy" explains why the open source movement may soon help mitigate the digital divide dynamic. Another essay illustrates the implementation of the "Get Us Connected" program in Africa, while a third considers the topic of "digital empowerment," a look at the "hole in the wall project" and efforts to deal with technological illiteracy. Finally, Part Six, called "Manifests and Agendas," looks at innovative projects like MISTICA, "a Latin America answer to the digital divide."

\section{Evaluation}

The book's editors and its contributors rightly regard the digital divide as an acute matter of social justice. They are not alone in reaching this conclusion. The United Nations, for example, certainly sees the digital divide, "the uneven distribution and use of new information and communication technologies," as a moral problem, since it impedes people and countries from entering the information age and perpetuates their impoverished condition ('The Real Digital Divide,' 2005). Without such access and connectivity, these people will continue to be marginalized since they cannot take advantage of the Internet's remarkable potential for communication 
as represented by new technologies such as Internet Protocol (IP) telephony.

Of course, as the trialog makes clear, the world is beset by many "divides," some of which are surely more serious than this one. We cannot address this matter of global poverty or inequities in more depth, but suffice it to say that the lack of computers and telephones is not the most pressing problem confronting developing countries. Hence, it is important to keep this particular inequity of a "digital divide" in proper perspective. As the editors of Vernetzt Gespalten observe in the opening trialog, "If [we] found ourselves in a southern town of the Sahara, our first thought would not be: 'there are no computers and connections here'. . . but we [would] say instead 'there are no adults here.' In southern Africa we find that the city of Darfur is inhabited almost exclusively by children, because the adults have all died of Aids." In this environment the need for health care and pharmaceuticals is far more urgent than the need for computers and telecommunications. Thus, while the book calls attention to the lack of computers and connectivity in countries such as Africa, it does not exaggerate the issue or blow it all out of proportion.

I am not so sure that all of the solutions proposed in this book for the closing of this great divide will necessarily succeed. For example, the advent of open source software or the emergence of a new "gift economy" (Geschenkökonomie) may help to some extent, since it will make some kinds of software more readily available in developing countries. But open source software is unlikely to be any panacea. Stallman (1998) has insisted that "there are other ways to encourage [software] development" besides reliance on a patent or a long copyright. But appealing to a software developer's powerful self-interest with the promise of a big reward for success, still stands out as the most viable means of stimulating the production of software products demanded by consumers. Thus, the future success of open source software and its potential to address the problem of information disparities depends upon the resolution of this critical incentive issue.

In summary, this book is a rich resource for anyone interested in understanding the scope of the immense digital divide problem along with some possible solutions. The selection and arrangement of the material enhances the book's attractiveness. The exposition of complex issues presented in those essays is lucid and provocative. Vernetzt gespalten's usefulness is severely limited, however, since the book is only available in German. Perhaps an English translation will appear and help solve this problem. But for those in the Anglo-Saxon world or in other communities who can read German, this book is well worth the effort.

\section{References}

Castells, M. (2001). The Internet Galaxy. New York: Oxford University Press.

'The Real Digital Divide,' (2005). The Economist March 12, $p 11$.

Stallman, R. (1998) Why Software Should be Free, available at: http://www. gnu.org/philosophy/shouldbefree.ht $\underline{m l}$

'All of the translations in this essay are the author's. 